\title{
Review Article \\ Differences in Multidisciplinary and Interdisciplinary Treatment Programs for Fibromyalgia: A Mapping Review
}

\author{
Emanuele Maria Giusti, ${ }^{1}$ Gianluca Castelnuovo, ${ }^{1,2}$ and Enrico Molinari ${ }^{1,2}$ \\ ${ }^{1}$ Department of Psychology, Catholic University of Milan, Milan, Italy \\ ${ }^{2}$ Istituto Auxologico Italiano IRCCS, Psychology Research Laboratory, San Giuseppe Hospital, Verbania, Italy \\ Correspondence should be addressed to Emanuele Maria Giusti; emanuelemaria.giusti@unicatt.it
}

Received 16 February 2017; Accepted 19 April 2017; Published 23 May 2017

Academic Editor: Manfred Harth

Copyright (C) 2017 Emanuele Maria Giusti et al. This is an open access article distributed under the Creative Commons Attribution License, which permits unrestricted use, distribution, and reproduction in any medium, provided the original work is properly cited.

\begin{abstract}
Fibromyalgia is a multifaceted chronic pain syndrome and the integration of different health disciplines is strongly recommended for its care. The interventions based on this principle are very heterogeneous and the difference across their structures has not been extensively studied, leading to incorrect conclusions when their outcomes are pooled. The objective of this mapping review was to summarize the characteristics of these programs, with particular focus on the integration of their components. We performed a search of the literature about treatments for fibromyalgia involving multiple disciplines on PubMed and Scopus. Starting from 560 articles, we included 22 noncontrolled studies, 10 controlled studies, and 17 RCTs evaluating the effects of 38 multidisciplinary or interdisciplinary interventions. The average quality of the studies was low. Their outcomes were usually pain intensity, quality of life, and psychological variables. We created a map of the programs based on the degree of integration of the included disciplines, which ranged from a juxtaposition of few components to a complex harmonization of different perspectives obtained through teamwork strategies. The rehabilitation programs were then thoroughly described with regard to the duration, setting, therapeutic components, and professionals included. The implications for future quantitative reviews are discussed.
\end{abstract}

\section{Introduction}

Fibromyalgia is a chronic pain condition of unknown etiology which affects mainly women and is characterized by stiffness, fatigue, disturbed sleep, cognitive impairment, and psychological distress, posing a significant threat to the quality of life of affected individuals [1-3]. The complex features of the syndrome and its various symptoms are partially explained by central sensitization processes that interact with psychological and social factors, leading to a phenomenon where the impact of each component is multiplied and acts in a synergic manner $[4,5]$. Given its multifaceted nature and the poor efficacy of standard medical interventions, the integration of different health disciplines for its understanding and for the development of specific treatments has long been advocated [6-10]. As a result, a large number of interventions combining techniques drawn from different fields (e.g., medicine, psychology, and physical therapy) have been developed and have proven to be effective for the improvement of the various symptoms of the syndrome [11-15]. Nonetheless, these programs are very heterogeneous in terms of duration, objectives, setting, format, therapeutic components, and professionals involved. This great variability is reflected by different organizational frameworks of the pain treatment facilities and casts some doubt on the possibility of pooling the results of trials evaluating their interventions $[16,17]$. The composition of the rehabilitation teams and the integration between their members seem to be especially important in distinguishing the various programs, since there is a wide difference with regard to how their various disciplines are harmonized, combined, or juxtaposed. Conversely, terms such as "multimodal," "multicomponent," "multidisciplinary," and "interdisciplinary" are often used as synonyms [18, 19]. From a theoretical point of view, the difference between these concepts is substantial. The terms "multimodal" and "multicomponent" have not received yet a clear definition. Multimodality generally refers to the combination of multiple therapeutic components, 
TABLE 1: Adapted SIGN checklist.

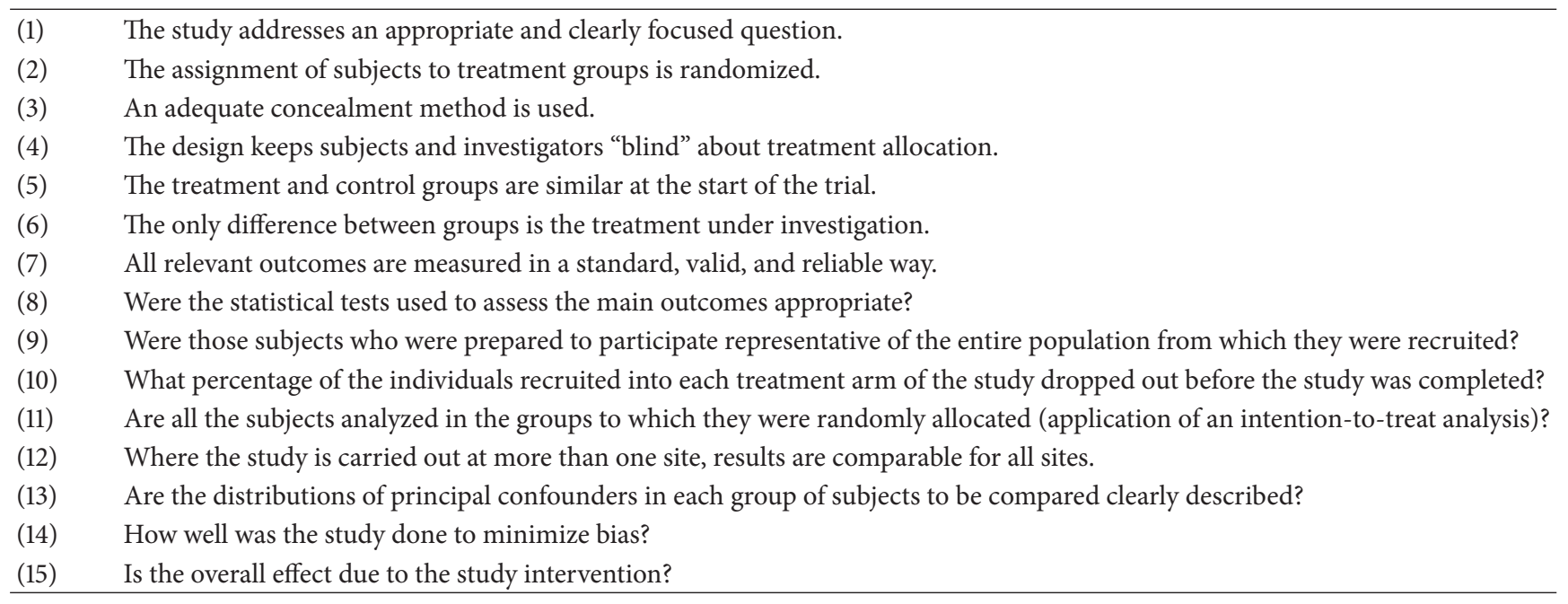

Note. During the assessment of noncontrolled studies, items from (2) to (6) were not considered.

not necessarily provided by different operators. The expression "multicomponent treatments" indicates the presence of interventions provided by different team members, without clarifying how they are integrated [20]. Conversely, the other two terms define how these components are combined. Multidisciplinarity refers to the addition of the competencies of multiple professionals who stay within the boundaries of their fields, whereas interdisciplinarity denotes that the various disciplines are coordinated toward a common and coherent approach [19]. Multidisciplinary and interdisciplinary treatments are therefore conceptually different and this difference should be reflected in their structures. Especially in the case of programs addressing a complex disorder, such as the fibromyalgia syndrome, this issue must be taken into account for the sake of a critical appraisal of the literature, which can be a preliminary step for quantitative synthesis. The objective of this review of the literature is therefore to describe, map, and summarize the characteristics of treatments for fibromyalgia involving multiple health disciplines, with a focus on how these disciplines are integrated.

\section{Methods}

A mapping review of the literature was performed. Mapping reviews usually aim to retrieve, catalog, and map all the evidence about a research topic [21, 22]. We adapted their methodological design in order to use rehabilitation programs as units of analysis. Therefore, instead of investigating the characteristics and the results of the included papers, we focused on the information about the interventions that were described.

We conducted a comprehensive search in PubMed and Scopus of all the available original research reports describing and evaluating multidisciplinary, interdisciplinary, or multicomponent interventions for fibromyalgia up to April 2016. We used these keywords in both databases: fibromyalgia, multidisciplinary, interdisciplinary, multicomponent, and integrated treatments. The studies were scanned according to the inclusion (description and evaluation of a multicomponent intervention involving at least two operators from different disciplines, fibromyalgia as primary diagnosis, and English language) and exclusion (review as publication type, single-case studies, and workplace interventions) criteria. Since our aim was to describe the various treatment programs and we were not interested in a quantitative evaluation of their outcomes, we included both RCTs, nonrandomized trials and noncontrolled trials. We also included studies evaluating outcome predictors, if they provided data about the effects of the interventions. A first scanning was based only on the titles and the abstracts of the retrieved research articles. After this first step, the full text of the remaining papers was accessed and we assessed the methodological quality of the studies. Since we included both controlled and noncontrolled trials, we adapted the SIGN checklist for randomized controlled trials [23] adding four items from the Downs and Black Checklist [24] (i.e., use of appropriate analyses, assessment of confounders, use of a representative sample, and intervention integrity) (Table 1). We used its scores to rate the studies as of "high," "medium," "low," and "insufficient" quality. Questions from 2 to 6 were not considered during the evaluation of noncontrolled studies.

We then employed a specifically created data extraction sheet to retrieve all the available information about number of study participants, dropout, professionals involved in the treatment, group/individual setting, inpatient/outpatient format, duration, components of the interventions, and treatment outcomes. When possible, we tried to locate and report the information about how the different disciplines are integrated with each other, in order to provide a brief outline of the program. In case of unclear or missing information, we initially tried to locate other descriptions consulting other studies of the same authors. If no other relevant studies were found, we tried to contact the authors of the articles and we asked them for additional information. All the data about the treatments were finally inserted in a MS Excel spreadsheet and were used to map the included interventions. 


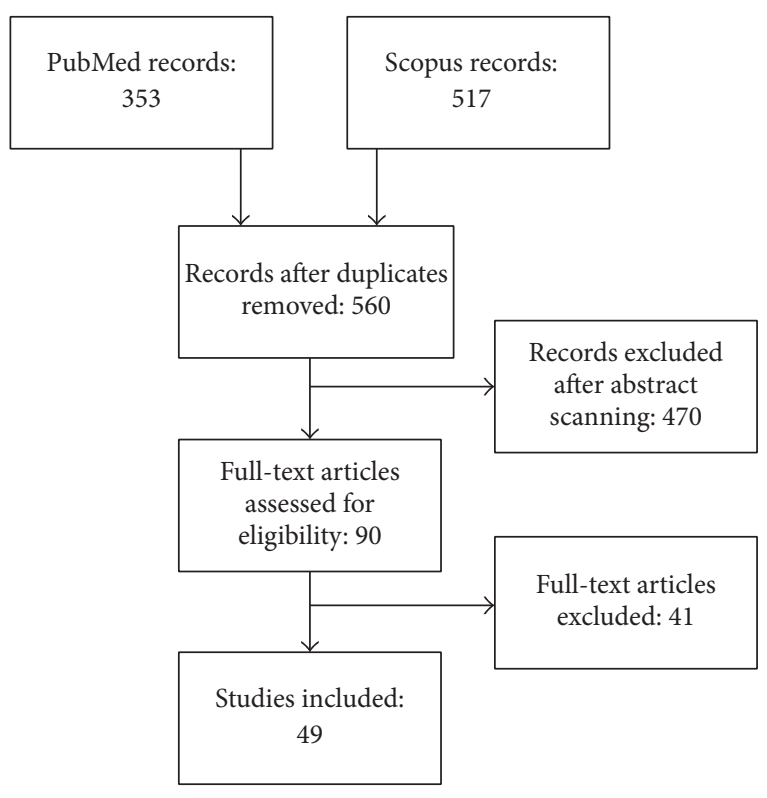

FIgURE 1: PRISMA flow chart diagram for study selection.

\section{Results}

3.1. Study Selection and Characteristics. The initial database search identified 560 records, of which 90 were selected for a full-text examination. The final database included 49 papers describing 38 different interventions that were administered to a total of 6013 subjects (Figure 1).

We found 22 papers describing noncontrolled studies, 10 describing controlled studies, and 17 describing RCTs (Table 2). The majority of the articles mainly reported the effects of a multicomponent treatment, whereas six papers mainly reported analyses on outcome predictors, one trial compared two multidisciplinary treatments, and three trials evaluated the effects of adding a treatment component to existing multidisciplinary treatments. The average methodological quality of the studies was low; 3 noncontrolled trials, 5 controlled trials, and 10 RCTs were rated as of medium quality and 6 studies were rated as of high quality. Their outcomes were usually pain intensity, psychological variables (such as anxiety, depression, distress, pain catastrophizing, coping skills, and self-efficacy), quality of life, and improvement in the overall score of the Fibromyalgia Impact Questionnaire.

\subsection{Multidisciplinary and Interdisciplinary Programs. Among} the studies included in the review, the terms "multimodal" and "multicomponent" were rarely employed and were never used as primary descriptors of the structure of the interventions, whereas 25 treatments were defined as "multidisciplinary" and 11 as "interdisciplinary." However, there was not a clear distinction between these concepts. In some cases, the terms were used interchangeably or were incorrectly employed (e.g., [71, 73] or [62]). More generally, the programs were very heterogeneous with regard to the strategies that were employed to integrate the different perspectives of the operators and can be mapped in a continuum which starts with multidisciplinary treatments involving few disciplines whose components are simply added and ends with more complex interventions that are based on a coordinated assessment and care (see Figure 2).

Most of the treatments were based on various components that were juxtaposed, so that the patient met the different health operators in different moments of the program in a standardized manner. A few interventions were more flexible and allowed the operators to tailor the programs, in terms of number and intensity of the therapeutic components, to the needs and characteristics of the patients. More integrated approaches were organized so that some or the majority of the treatment sessions were led by two or more professionals jointly. In other cases, weekly team meetings were planned to discuss the patients, allowing a constant dialog between the operators. This could be added to other strategies, such as providing education about interdisciplinary work or tailoring the various components to the patients, in order to provide more effective integration of the different disciplines.

3.3. Description of the Interventions. The main characteristics of the interventions are reported in Table 3. Most of the programs were based on an outpatient setting; only five intensive treatments were provided in hospital inpatient services. Only four programs were mainly administered individually, six interventions included both group and individual activities, and the other 28 treatments were mainly group-based. There was a great variety with regard to the duration and the intensity of the interventions. The median duration was 7 weeks, but there were both very brief treatments lasting for less than a week (e.g., [70]) and very long treatments lasting for one year (e.g., [27]). With regard to the intensity, there were both intensive programs (e.g., [28]) and interventions including less than twelve hours of therapies (e.g., [70]), with a median of 42 hours of treatment.

The number and the choice of the disciplines that were integrated in the various interventions were very variable, as well as their relative importance. As a consequence, it was not possible to categorize the programs creating clusters based on the professionals included. Physicians, physical therapists, and psychologists were the most employed operators, followed by occupational therapists, nurses, social workers, dietitians, and other professionals such as Qi-gong instructors, kinesiologists, and massage therapists.

The main therapeutic components included in the various rehabilitation programs were education about fibromyalgia and physical exercise, which were present in 36 out of 38 programs. Education was generally based on group lectures about the syndrome, its symptoms, its prognosis, and the biopsychosocial factors influencing its long-term progression and its daily course. The prescribed physical activity was various and included aerobic, pool, and strengthening exercises. 19 programs provided some psychotherapy sessions under the cognitive-behavioral approach, generally focused on symptom management. Both the educational lectures and the psychotherapeutic sessions could also be focused on teaching the patients to self-manage their symptoms 


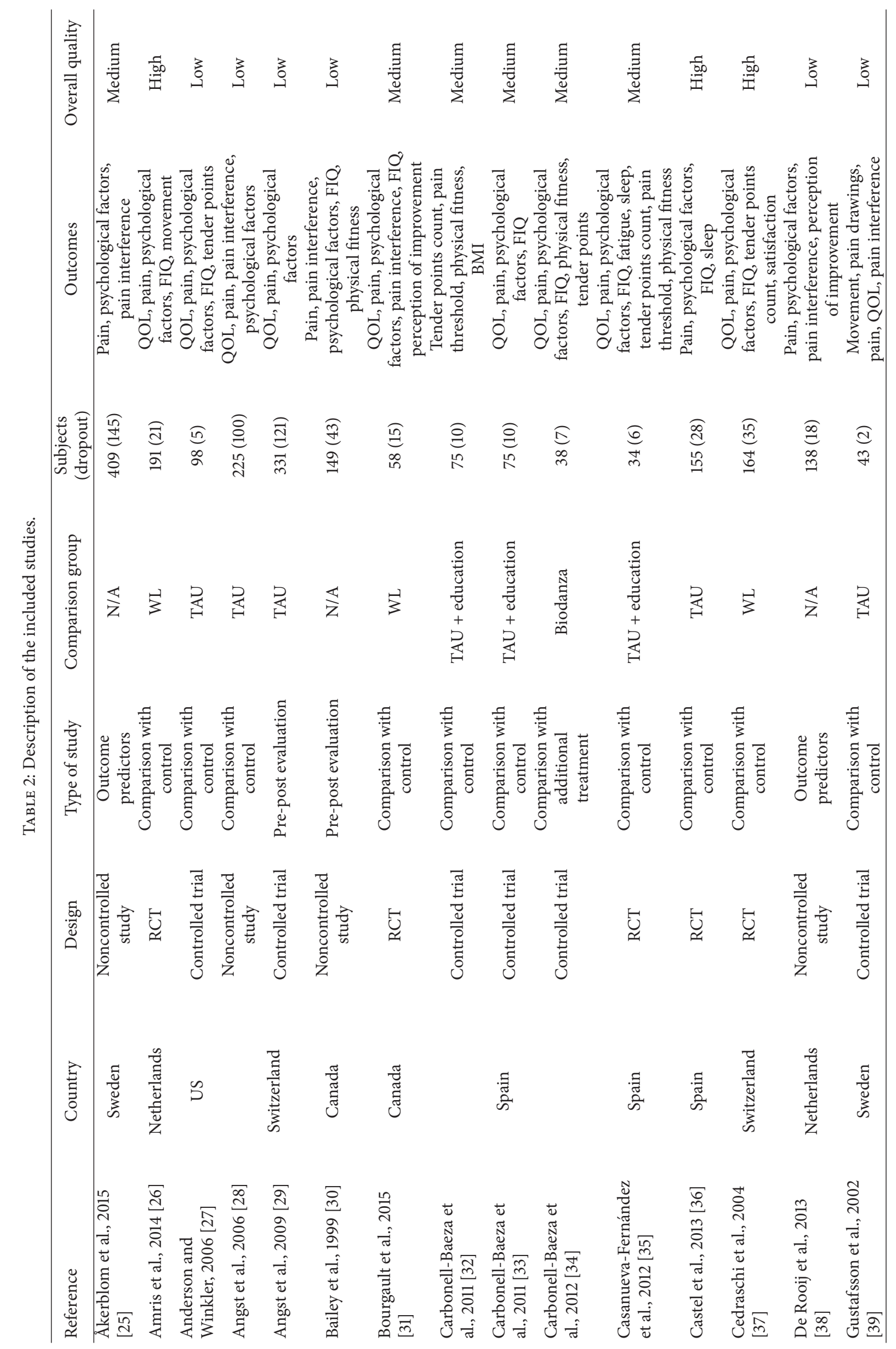




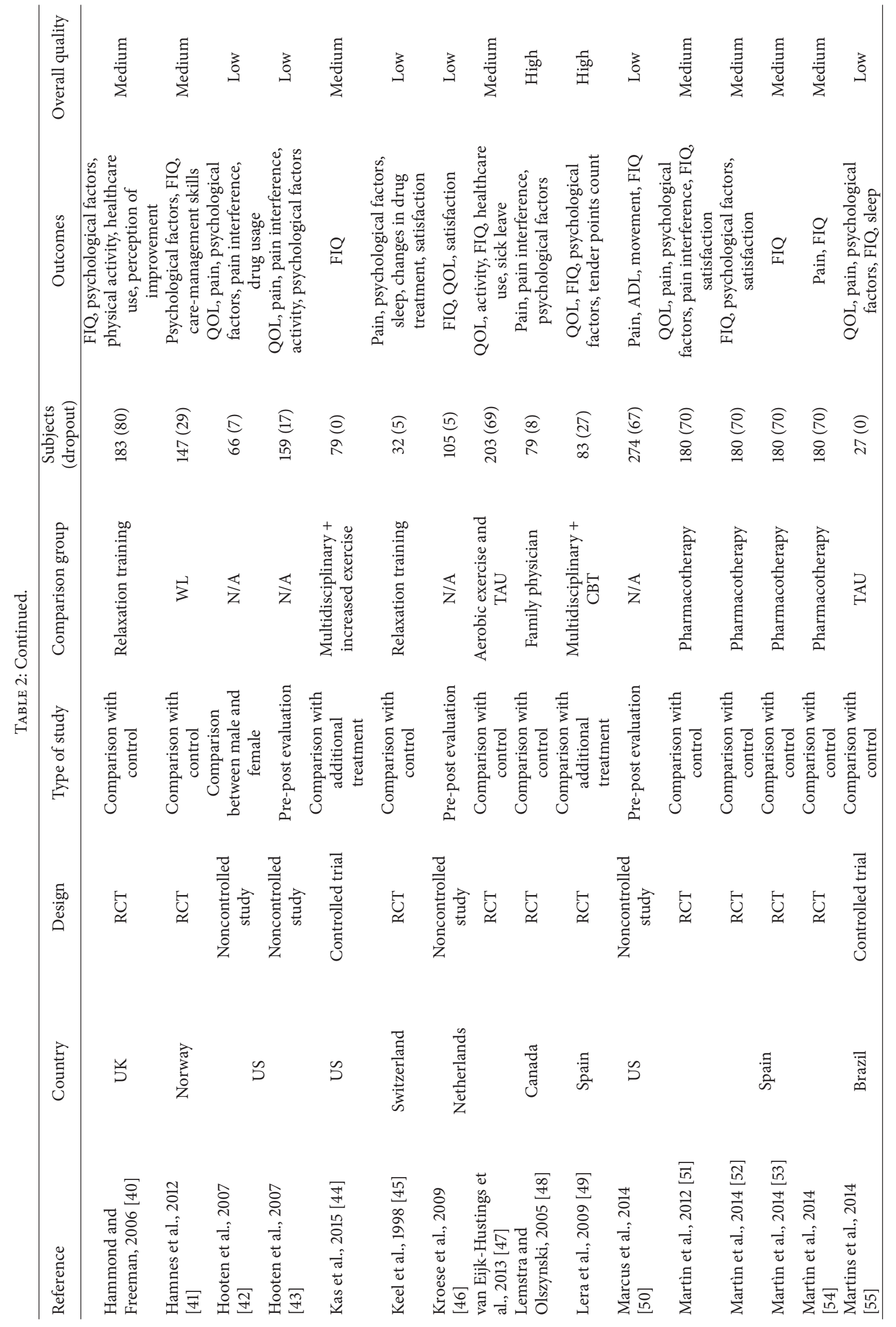




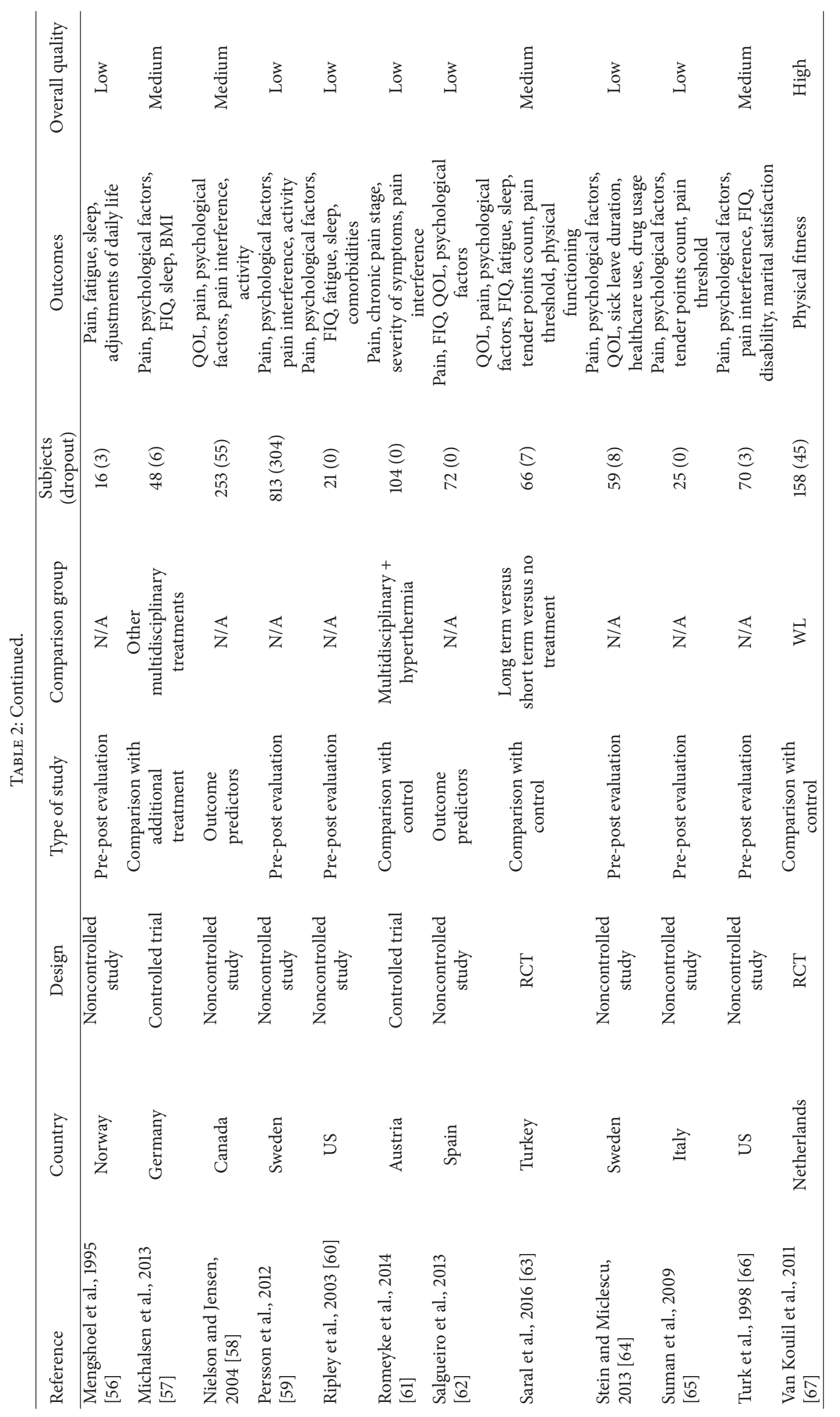




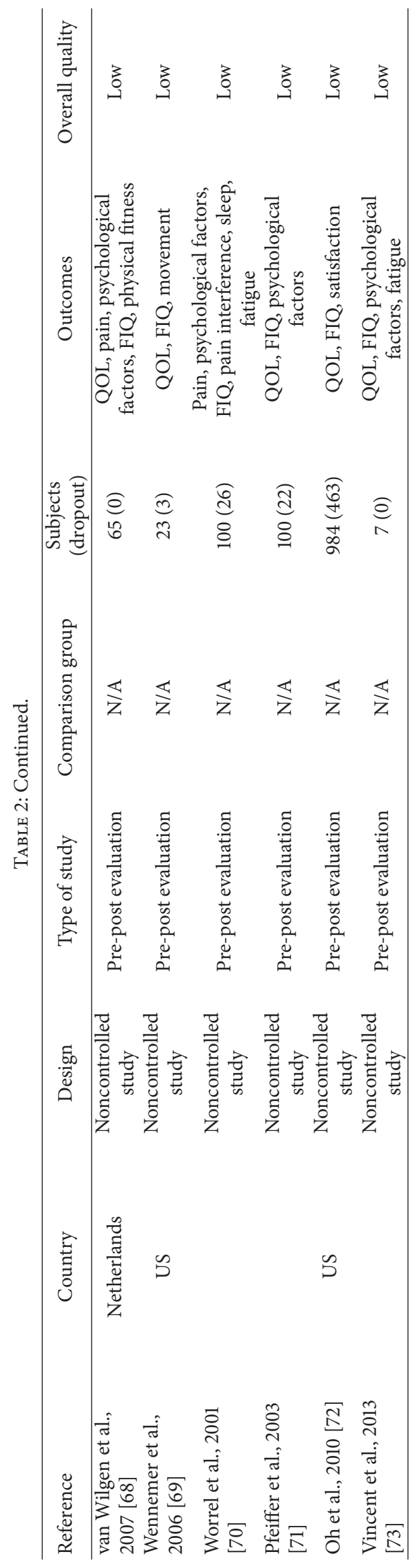




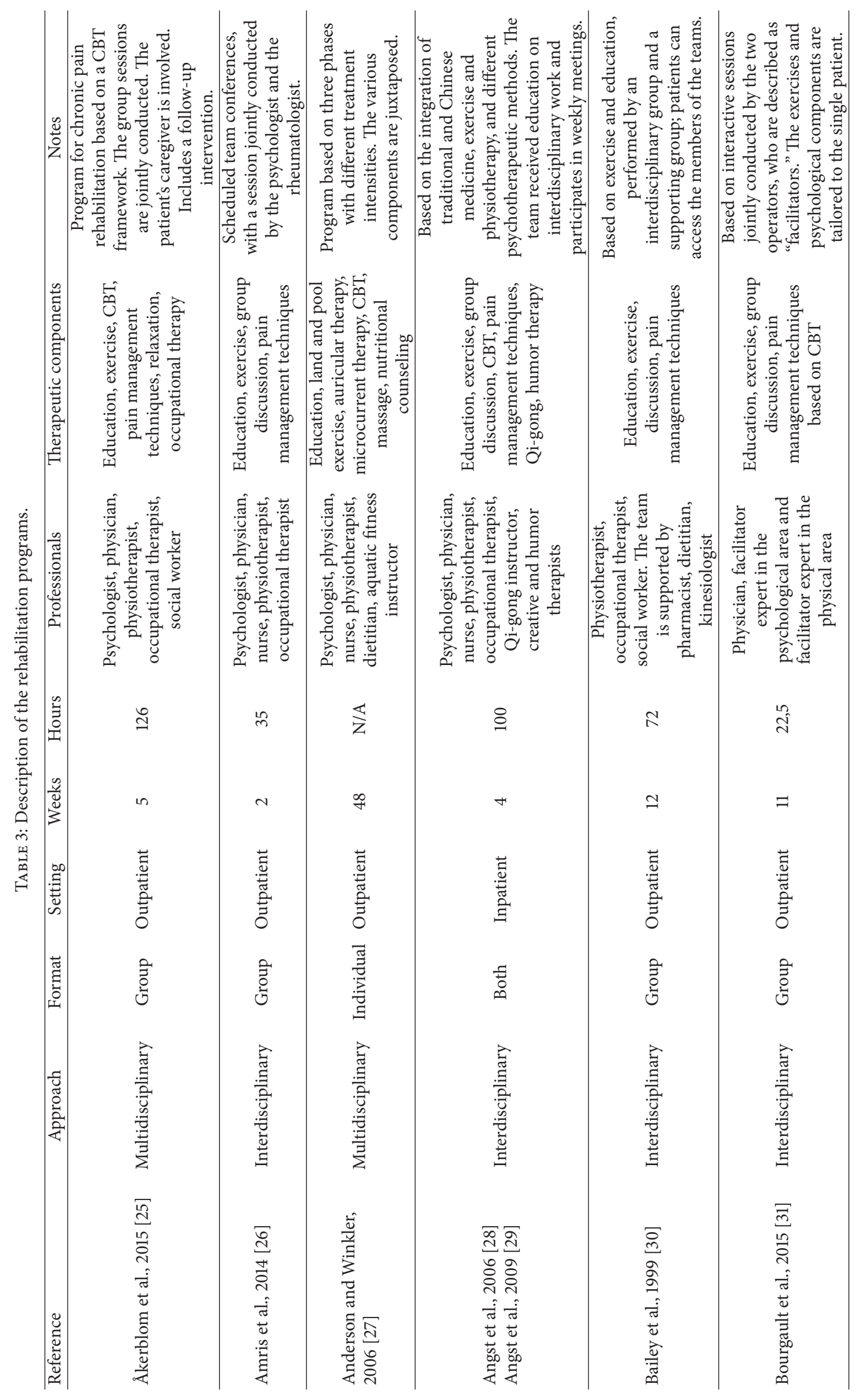




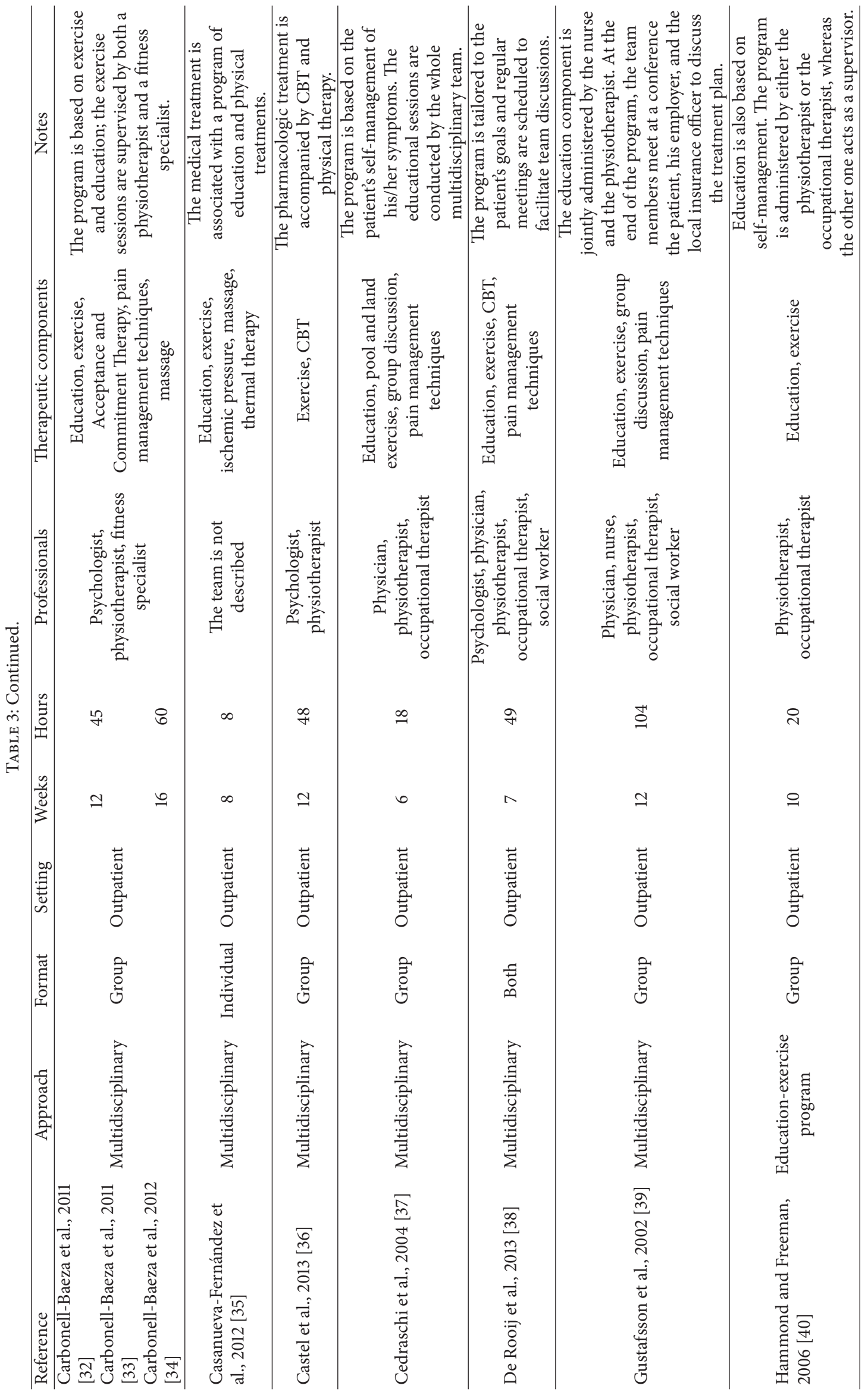




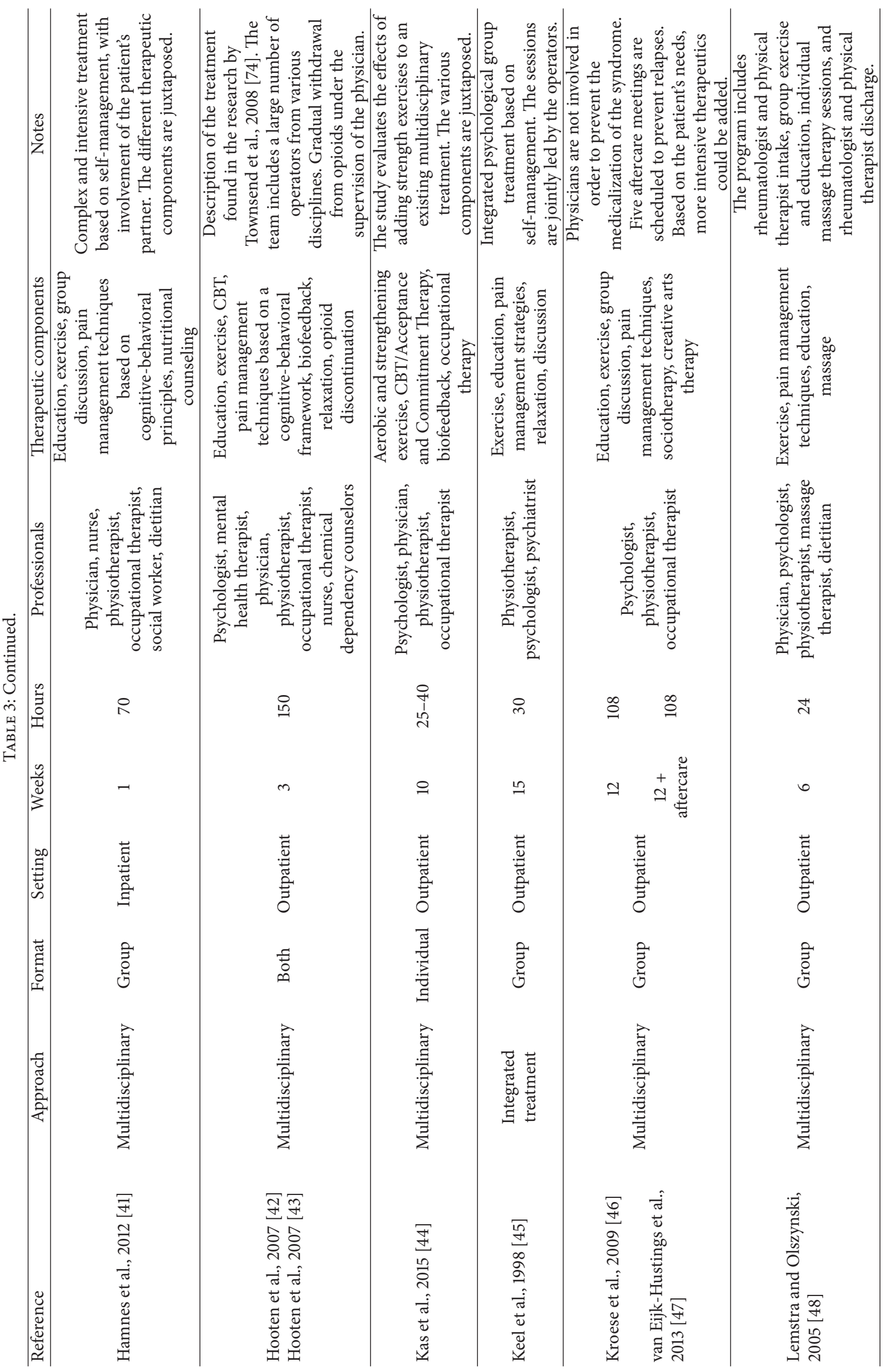




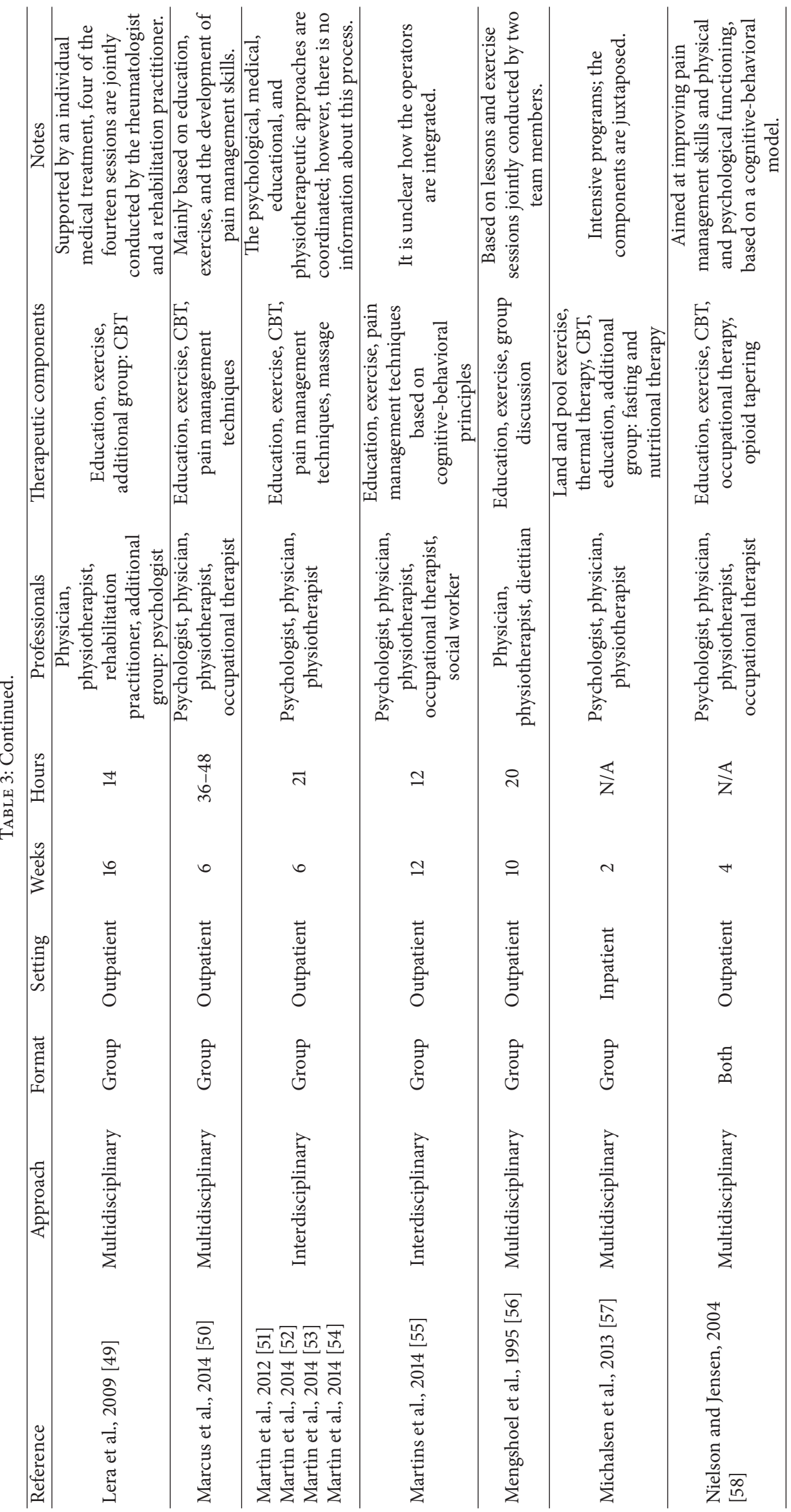




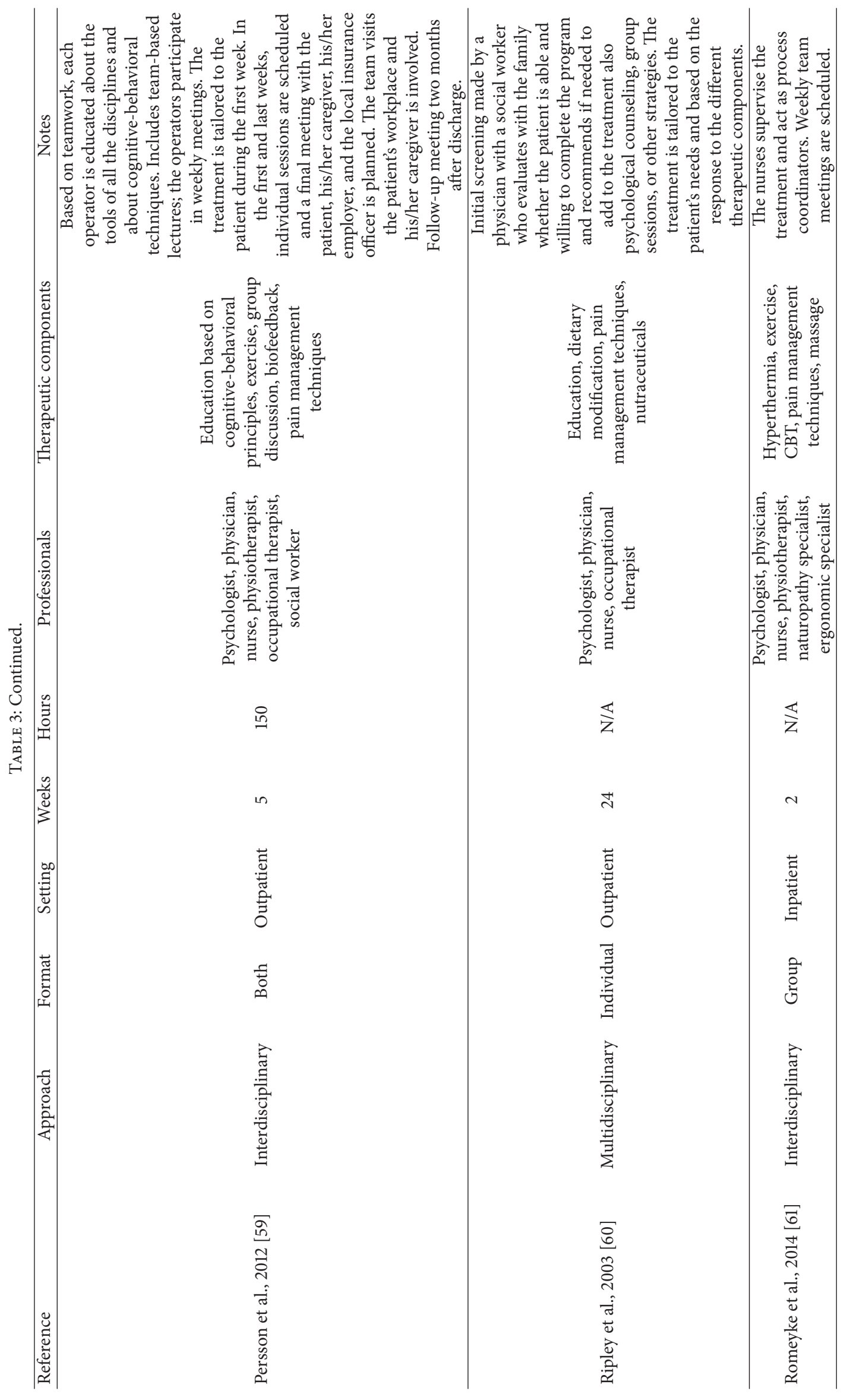




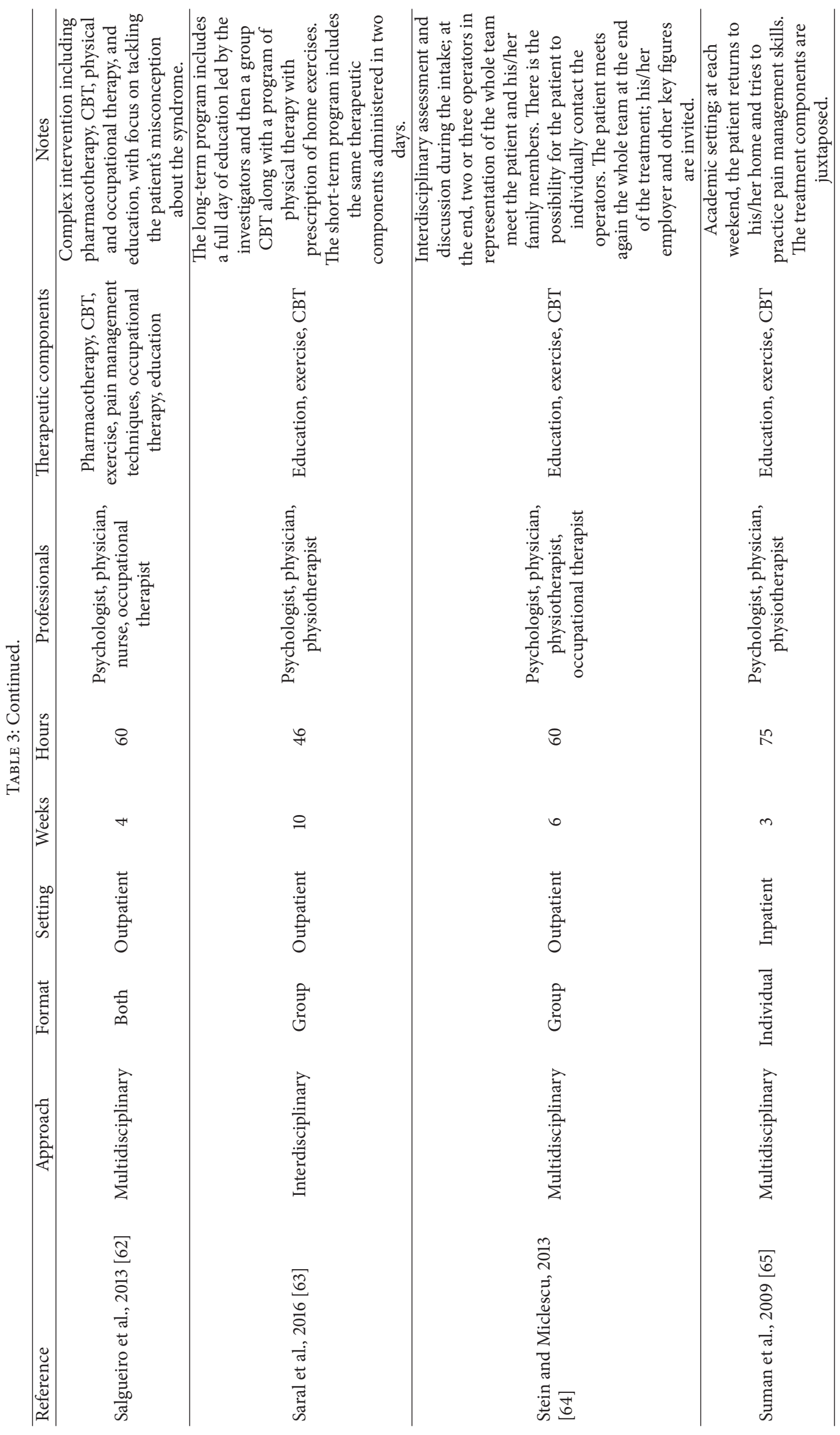




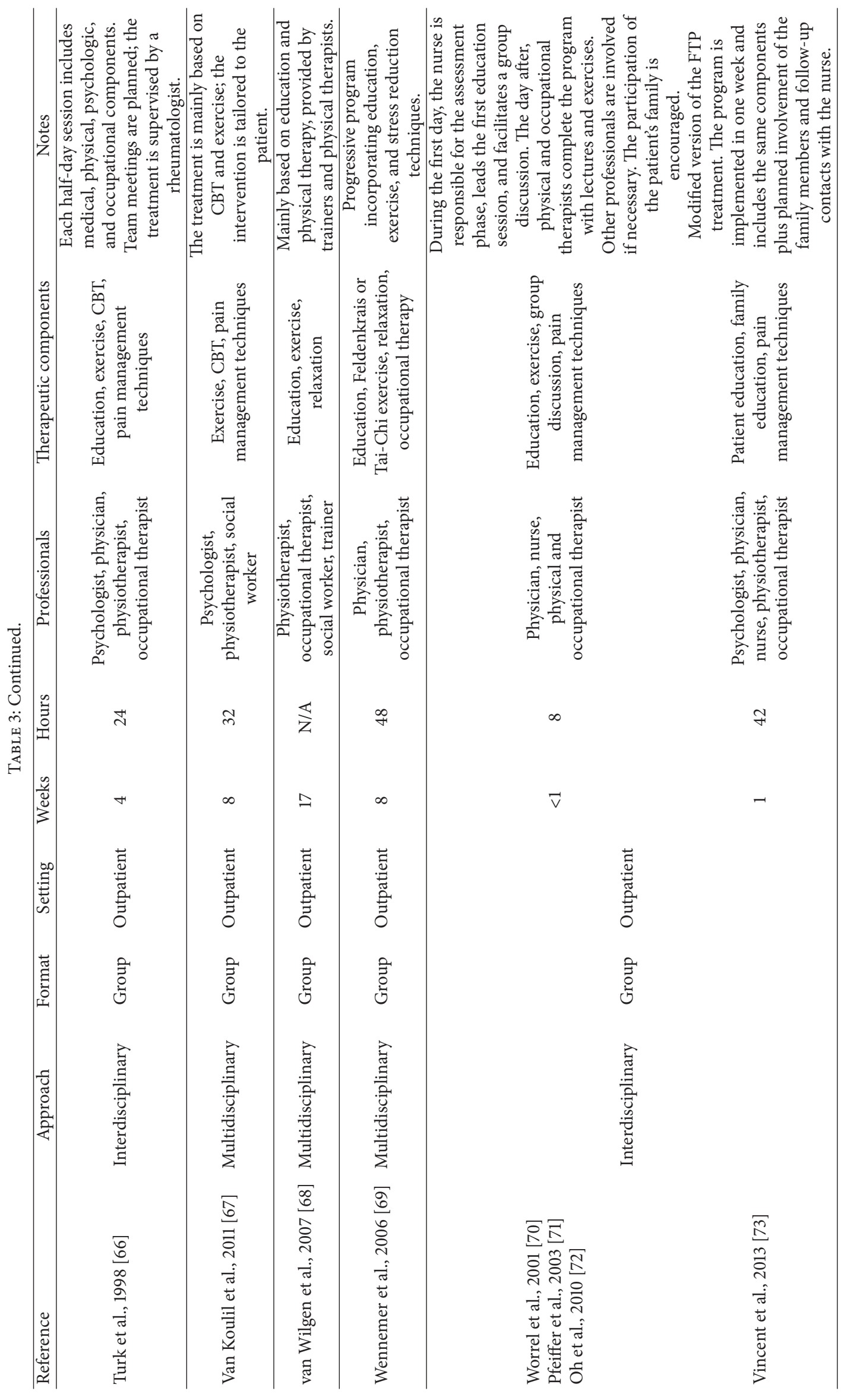




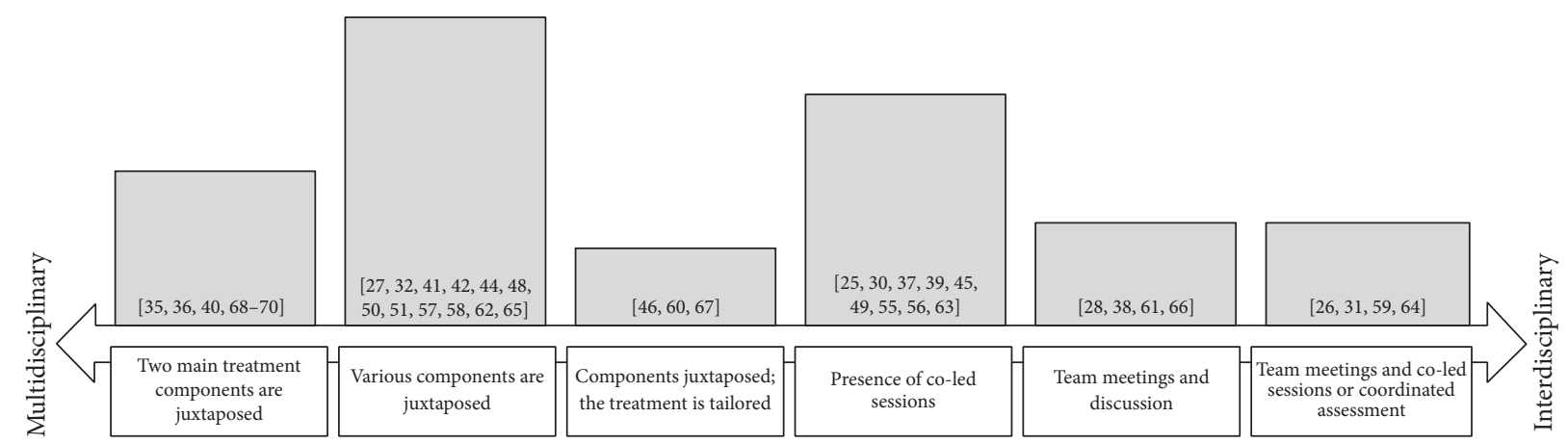

FIGURE 2: Map of the rehabilitation programs. Note. The height of the bars is proportional to the frequency of the interventions included in the relative category. The references of the studies describing these interventions are in brackets.

and on enhancing group discussions among the participants. Besides these common therapeutic components, other forms of interventions were usually provided. These include, for instance, occupational therapies, biofeedback, massage therapies, relaxation, Acceptance and Commitment Therapy sessions, and dietary counseling.

\section{Discussion}

The objective of this review was to describe the characteristics of the available integrated interventions for fibromyalgia, focusing on how the different disciplines are integrated with each other. Our study, therefore, is embedded in two lines of inquiry, that is, the discussion about multidisciplinarity and interdisciplinarity in the healthcare and the evaluation of multicomponent treatment for chronic pain conditions.

With regard to the first, our study is in line with and finds support for the predominant theoretical perspective which describes multidisciplinarity and interdisciplinarity as two parts of the same continuum $[18,19]$. Employing the original perspective of analyzing how the integration of the different disciplines is provided by the various programs, we found that the possible organizational frameworks are multiple and are characterized by different degrees of complexity. On the one hand, less integrated programs provide a juxtaposition of two or more different disciplines, which are simply added. These programs can be seen as the prototype of multidisciplinary interventions, since every operator works independently, there is no overlap between the different treatment modalities, and the program is generally organized in a vertical manner [75]. However, we found that there are multidisciplinary programs which use a more flexible and integrated framework, which allows us to modify the treatment and to involve the patient in the decisions about his/her care. In more cohesive programs, some or the majority of the education or pain management sessions are jointly conducted by different operators, allowing the professionals to build a shared perspective regarding the various topics. Prototypical interdisciplinary models seem however to be based on weekly team discussions about the patients, which can be accompanied by other strategies, such as education about interdisciplinary work, a coordinated assessment, or providing sessions jointly conducted by the operators. The presence of team meetings seems to be considered by the authors of the studies included in this review as the main characteristic which defines their treatment as "interdisciplinary," partly overlooking other components such as creating common goals, making team conferences with the patient and his/her family, and providing shared leadership and a comprehensive assessment $[75,76]$.

With regard to the evaluation of the multicomponent interventions for fibromyalgia, our study represents a first step for conducting a quantitative synthesis of the literature. As we had hypothesized, we found that the programs included in our review were very heterogeneous in terms of number, type, and integration of the components and professionals, as well as in terms of duration and intensity. Previous analyses of the literature did not successfully address this diversity. Hauser and colleagues [20] performed a metaanalysis on 7 RCTs evaluating multicomponent treatments for fibromyalgia, finding support for their short-term efficacy. The author conducted a sensitivity analysis based only on the methodologic quality and the duration of the programs. A previous Cochrane review [77] attempted to include all the interventions which contained both a medical and a psychological, social, or vocational component, finding four RCTs and showing that these interventions did not provide quantifiable benefits. Different from our study, the authors did not address the differences with regard to format, setting of the program, and integration of operators and therapeutic components. More recently, Papadopoulou et al. [11] evaluated all the pharmacological and nonpharmacological interventions for fibromyalgia, finding support for multidisciplinary treatments based on 8 RCTs, which were not described. Similarly, other reviews focusing on various chronic pain conditions found that multicomponent programs are effective for the treatment of fibromyalgia but did not address their heterogeneity [12, 78]. Our study was not aimed at a quantitative evaluation of the outcomes of these programs but provides a detailed description of the various programs identifying some key characteristics that must be taken into account by future systematic reviews and meta-analyses. In particular, the most varying factors were the duration and the intensity of the programs, the 
treatment components, and the strategies of integration of the operators. It is needed that future quantitative reviews separately analyze studies evaluating treatments with different structures and assess the moderator effect of the temporal characteristics of the programs.

Some important remarks need to be made. On the one hand, we focused only on studies which included multiple disciplines performed by multiple operators. Therefore, we excluded the papers which did not state clearly that multiple professionals were present and we focused on programs performed by rehabilitation teams. As a consequence, our description is limited to these treatments and it is possible that some multidisciplinary programs were excluded due to poor descriptions of their structure. In addition, our findings are based on brief reports included in scientific papers, and it is possible that important characteristics of the evaluated interventions were missing and that the whole of the multidisciplinary and interdisciplinary rehabilitation programs is misrepresented by our sample. Finally, our electronic search was limited to two databases and to papers written in English language, limiting the comprehensiveness of the review.

However, to our knowledge, this is the first study which attempts to map the characteristics of multicomponent interventions for fibromyalgia. In addition, performing this mapping review allowed us to create a comprehensive database of studies that can be used for further analyses and that is available upon request. We are persuaded that the integration of the various disciplines is a key factor for the treatment of such a condition. It is possible that the more the perspectives of the various professionals are integrated, the more the patients are able to comprehend the complexity of their syndrome and can be conscious about how the different biological, psychological, and social factors affect its course.

\section{Conclusions}

Multidisciplinary and interdisciplinary treatments must be considered as two ends of the same continuum. The degrees of integration of their component do not depend only on the juxtaposition or on the overlap between the various competences but rely on the possibility of tailoring the programs to the patients or on the presence of co-led sessions, team meetings, and a coordinate assessment. The various studies are very heterogeneous with regard to most of the variables described in our review. This diversity will need to be taken into account by future quantitative reviews of the literature.

\section{Conflicts of Interest}

The authors declare that there are no conflicts of interest regarding the publication of this paper.

\section{Acknowledgments}

The authors would like to thank Dr. Giorgio Cruccu for comments that greatly improved the manuscript.

\section{References}

[1] H. S. Smith, R. Harris, and D. Clauw, "Fibromyalgia: an afferent processing disorder leading to a complex pain generalized syndrome," Pain Physician, vol. 14, no. 2, pp. E217-E245, 2011.

[2] A. Rahman, M. Underwood, and D. Carnes, "Fibromyalgia," The British Medical Journal, vol. 348, Article ID g1224, 2014.

[3] D. J. Clauw, "Fibromyalgia and related conditions," Mayo Clinic Proceedings, vol. 90, no. 5, pp. 680-692, 2015.

[4] M. B. Yunus, "Central sensitivity syndromes: a new paradigm and group nosology for fibromyalgia and overlapping conditions, and the related issue of disease versus illness," Seminars in Arthritis and Rheumatism, vol. 37, no. 6, pp. 339-352, 2008.

[5] G. Cassisi, P. Sarzi-Puttini, R. Casale et al., "Pain in fibromyalgia and related conditions," Reumatismo, vol. 66, no. 1, pp. 72-86, 2014.

[6] J. Ablin, M. A. Fitzcharles, D. Buskila, Y. Shir, C. Sommer, and W. Häuser, "Treatment of fibromyalgia syndrome: recommendations of recent evidence-based interdisciplinary guidelines with special emphasis on complementary and alternative therapies," Evidence-Based Complementary and Alternative Medicine, vol. 2013, Article ID 485272, 7 pages, 2013.

[7] D. L. Goldenberg, "Management of fibromyalgia syndrome," Rheumatic Disease Clinics of North America, vol. 15, no. 3, pp. 499-512, 1989.

[8] D. L. Goldenberg, "Fibromyalgia, chronic fatigue syndrome, and myofascial pain syndrome," Current Opinion in Rheumatology, vol. 9, no. 2, pp. 135-143, 1997.

[9] W. Hauser, J. Ablin, M. A. Fitzcharles et al., "Fibromyalgia," Nature Reviews Disease Primers, vol. 1, Article ID 15022, 2015.

[10] G. Castelnuovo, E. M. Giusti, G. M. Manzoni et al., "Psychological considerations in the assessment and treatment of pain in neurorehabilitation and psychological factors predictive of therapeutic response: evidence and recommendations from the italian consensus conference on pain in neurorehabilitation," Frontiers in Psychology, vol. 7, p. 468, 2016.

[11] D. Papadopoulou, A. Fassoulaki, C. Tsoulas, I. Siafaka, and A. Vadalouca, "A meta-analysis to determine the effect of pharmacological and non-pharmacological treatments on fibromyalgia symptoms comprising OMERACT-10 response criteria," Clinical Rheumatology, vol. 35, no. 3, pp. 573-586, 2016.

[12] L. Scascighini, V. Toma, S. Dober-Spielmann, and H. Sprott, "Multidisciplinary treatment for chronic pain: a systematic review of interventions and outcomes," Rheumatology, vol. 47, no. 5, pp. 670-678, 2008.

[13] G. Castelnuovo, E. M. Giusti, G. M. Manzoni et al., "Psychological treatments and psychotherapies in the neurorehabilitation of pain: evidences and recommendations from the italian consensus conference on pain in neurorehabilitation," Frontiers in Psychology, vol. 7, p. 115, 2016.

[14] E. Nüesch, W. Häuser, K. Bernardy, J. Barth, and P. Jüni, "Comparative efficacy of pharmacological and nonpharmacological interventions in fibromyalgia syndrome: network meta-analysis," Annals of the Rheumatic Diseases, vol. 72, no. 6, pp. 955-962, 2013.

[15] S. Tamburin, M. R. Lacerenza, G. Castelnuovo et al., "Pharmacological and non-pharmacological strategies in the integrated treatment of pain in neurorehabilitation. Evidence and recommendations from the italian consensus conference on pain in neurorehabilitation," European Journal of Physical and Rehabilitation Medicine, vol. 52, no. 5, pp. 741-752, 2016. 
[16] S. R. Fashler, L. K. Cooper, E. D. Oosenbrug et al., "Systematic review of multidisciplinary chronic pain treatment facilities," Pain Research and Management, vol. 2016, Article ID 5960987, 19 pages, 2016.

[17] P. Peng, J. N. Stinson, M. Choiniere et al., "Role of health care professionals in multidisciplinary pain treatment facilities in Canada," Pain Research \& Management, vol. 13, no. 6, pp. 484488, 2008.

[18] C. M. Scott and A. T. Hofmeyer, "Acknowledging complexity: critically analyzing context to understand interdisciplinary research," Journal of Interprofessional Care, vol. 21, no. 5, pp. 491501, 2007.

[19] B. C. Choi and A. W. Pak, "Multidisciplinarity, interdisciplinarity and transdisciplinarity in health research, services, education and policy: 1 . Definitions, objectives, and evidence of effectiveness," Clinical and Investigative Medicine, vol. 29, no. 6, pp. 351-364, 2006.

[20] W. Hauser, K. Bernardy, B. Arnold, M. Offenbacher, and M. Schiltenwolf, "Efficacy of multicomponent treatment in fibromyalgia syndrome: a meta-analysis of randomized controlled clinical trials," Arthritis \& Rheumatology, vol. 61, no. 2, pp. 216-224, 2009.

[21] M. J. Grant and A. Booth, "A typology of reviews: an analysis of 14 review types and associated methodologies," Health Information \& Libraries Journal, vol. 26, no. 2, pp. 91-108, 2009.

[22] K. L. James, N. P. Randall, and N. R. Haddaway, "A methodology for systematic mapping in environmental sciences," Environmental Evidence, vol. 5, no. 1, pp. 1-13, 2016.

[23] SIGN, "Methodology checklist 2: randomised controlled trials," http://www.sign.ac.uk/methodology/checklists.html.

[24] S. H. Downs and N. Black, "The feasibility of creating a checklist for the assessment of the methodological quality both of randomised and non-randomised studies of health care interventions," Journal of Epidemiology and Community Health, vol. 52, no. 6, pp. 377-384, 1998.

[25] S. Åkerblom, S. Perrin, M. Rivano Fischer, and L. M. McCracken, "The mediating role of acceptance in multidisciplinary cognitive-behavioral therapy for chronic pain," The Journal of Pain, vol. 16, no. 7, pp. 606-615, 2015.

[26] K. Amris, E. E. Wæhrens, R. Christensen, H. Bliddal, and B. Danneskiold-Samsøe, "Interdisciplinary rehabilitation of patients with chronic widespread pain: primary endpoint of the randomized, nonblinded, parallel-group IMPROvE trial," Pain, vol. 155, no. 7, pp. 1356-1364, 2014.

[27] F. J. Anderson and A. E. Winkler, "Benefits of long-term fibromyalgia syndrome treatment with a multidisciplinary program," Journal of Musculoskeletal Pain, vol. 14, no. 4, pp. 11-25, 2006.

[28] F. Angst, R. Brioschi, C. J. Main, S. Lehmann, and A. Aeschlimann, "Interdisciplinary rehabilitation in fibromyalgia and chronic back pain: a prospective outcome study," The Journal of Pain, vol. 7, no. 11, pp. 807-815, 2006.

[29] F. Angst, M. L. Verra, S. Lehmann, R. Brioschi, and A. Aeschlimann, "Clinical effectiveness of an interdisciplinary pain management programme compared with standard inpatient rehabilitation in chronic pain: a naturalistic, prospective controlled cohort study," Journal of Rehabilitation Medicine, vol. 41, no. 7, pp. 569-575, 2009.

[30] A. Bailey, L. Starr, M. Alderson, and J. Moreland, "A comparative evaluation of a fibromyalgia rehabilitation program," Arthritis Care and Research, vol. 12, no. 5, pp. 336-340, 1999.
[31] P. Bourgault, A. Lacasse, S. Marchand et al., "Multicomponent interdisciplinary group intervention for self-management of fibromyalgia: a mixed-methods randomized controlled trial," PLoS ONE, vol. 10, no. 5, Article ID 0126324, 2015.

[32] A. Carbonell-Baeza, V. A. Aparicio, P. Chillón, P. Femia, M. Delgado-Fernández, and J. R. Ruiz, "Effectiveness of multidisciplinary therapy on symptomatology and quality of life in women with fibromyalgia," Clinical and Experimental Rheumatology, vol. 29, no. 6, supplement 69, pp. S97-S103, 2011.

[33] A. Carbonell-Baeza, V. A. Aparicio, F. B. Ortega et al., "Does a 3-month multidisciplinary intervention improve pain, body composition and physical fi tness in women with fibromyalgia?" British Journal of Sports Medicine, vol. 45, no. 15, pp. 1189-1195, 2011.

[34] A. Carbonell-Baeza, J. R. Ruiz, V. A. Aparicio et al., "Multidisciplinary and biodanza intervention for the management of fibromyalgia," Acta Reumatologica Portuguesa, vol. 37, no. 3, pp. 240-250, 2012.

[35] B. Casanueva-Fernández, J. Llorca, J. B. I. Rubió, B. RoderoFernández, and M. A. González-Gay, "Efficacy of a multidisciplinary treatment program in patients with severe fibromyalgia," Rheumatology International, vol. 32, no. 8, pp. 2497-2502, 2012.

[36] A. Castel, R. Fontova, S. Montull et al., "Efficacy of a multidisciplinary fibromyalgia treatment adapted for women with low educational levels: a randomized controlled trial," Arthritis Care \& Research, vol. 65, no. 3, pp. 421-431, 2013.

[37] C. Cedraschi, J. Desmeules, E. Rapiti et al., "Fibromyalgia: a randomised, controlled trial of a treatment programme based on self management," Annals of the Rheumatic Diseases, vol. 63, no. 3, pp. 290-296, 2004.

[38] A. De Rooij, M. Van Der Leeden, L. D. Roorda, M. P. M. Steultjens, and J. Dekker, "Predictors of outcome of multidisciplinary treatment in chronic widespread pain: an observational study," BMC Musculoskeletal Disorders, vol. 14, 2013.

[39] M. Gustafsson, J. Ekholm, and L. Broman, "Effects of a multiprofessional rehabilitation programme for patients with fibromyalgia syndrome," Journal of Rehabilitation Medicine, vol. 34 , no. 3, pp. 119-127, 2002.

[40] A. Hammond and K. Freeman, "Community patient education and exercise for people with fibromyalgia: a parallel group randomized controlled trial," Clinical Rehabilitation, vol. 20, no. 10, pp. 835-846, 2006.

[41] B. Hamnes, P. Mowinckel, I. Kjeken, and K. B. Hagen, "Effects of a one week multidisciplinary inpatient self-management programme for patients with fibromyalgia: a randomised controlled trial," BMC Musculoskeletal Disorders, vol. 13, 2012.

[42] W. M. Hooten, C. O. Townsend, C. D. Sletten, B. K. Bruce, and J. D. Rome, “Treatment outcomes after multidisciplinary pain rehabilitation with analgesic medication withdrawal for patients with fibromyalgia," Pain Medicine, vol. 8, no. 1, pp. 8-16, 2007.

[43] W. M. Hooten, C. O. Townsend, and P. A. Decker, "Gender differences among patients with fibromyalgia undergoing multidisciplinary pain rehabilitation," Pain Medicine, vol. 8, no. 8, pp. 624-632, 2007.

[44] T. Kas, M. Colby, M. Case, and D. Vaughn, "The effect of extremity strength training on fibromyalgia symptoms and disease impact in an existing multidisciplinary treatment program," Journal of Bodywork and Movement Therapies, vol. 20, no. 4, pp. 774-783, 2015.

[45] P. J. Keel, C. Bodoky, U. Gerhard, and W. Müller, "Comparison of integrated group therapy and group relaxation training for 
fibromyalgia," Clinical Journal of Pain, vol. 14, no. 3, pp. 232238, 1998.

[46] M. Kroese, G. Schulpen, M. Bessems, F. Nijhuis, J. Severens, and R. Landewé, "The feasibility and efficacy of a multidisciplinary intervention with aftercare meetings for fibromyalgia," Clinical Rheumatology, vol. 28, no. 8, pp. 923-929, 2009.

[47] Y. van Eijk-Hustings, M. Kroese, F. Tan, A. Boonen, M. Bessems-Beks, and R. Landewé, "Challenges in demonstrating the effectiveness of multidisciplinary treatment on quality of life, participation and health care utilisation in patients with fibromyalgia: a randomised controlled trial," Clinical Rheumatology, vol. 32, no. 2, pp. 199-209, 2013.

[48] M. Lemstra and W. P. Olszynski, "The effectiveness of multidisciplinary rehabilitation in the treatment of fibromyalgia: A randomized controlled trial," Clinical Journal of Pain, vol. 21, no. 2, pp. 166-174, 2005.

[49] S. Lera, S. M. Gelman, M. J. López et al., "Multidisciplinary treatment of fibromyalgia: does cognitive behavior therapy increase the response to treatment?" Journal of Psychosomatic Research, vol. 67, no. 5, pp. 433-441, 2009.

[50] D. A. Marcus, C. D. Bernstein, A. Haq, and P. Breuer, "Including a range of outcome targets offers a broader view of fibromyalgia treatment outcome: Results from a retrospective review of multidisciplinary treatment," Musculoskeletal Care, vol. 12, no. 2, pp. 74-81, 2014.

[51] J. Martín, F. Torre, A. Padierna et al., "Six-and 12-month followup of an interdisciplinary fibromyalgia treatment programme: results of a randomised trial," Clinical and Experimental Rheumatology, vol. 30, supplement 74, pp. S103-S111, 2012.

[52] J. Martín, F. Torre, U. Aguirre et al., "Evaluation of the interdisciplinary PSYMEPHY treatment on patients with fibromyalgia: a randomized control trial," Pain Medicine, vol. 15, no. 4, pp. 682691, 2014.

[53] J. Martín, F. Torre, A. Padierna et al., "Impact of interdisciplinary treatment on physical and psychosocial parameters in patients with fibromyalgia: results of a randomised trial," International Journal of Clinical Practice, vol. 68, no. 5, pp. 618627, 2014.

[54] J. Martín, F. Torre, A. Padierna et al., "Interdisciplinary treatment of patients with fibromyalgia: improvement of their health-related quality of life," Pain Practice, vol. 14, no. 8, pp. 721-731, 2014.

[55] M. R. I. Martins, C. C. Gritti, R. dos Santos Junior et al., "Randomized controlled trial of a therapeutic intervention group in patients with fibromyalgia syndrome," Revista Brasileira de Reumatologia, vol. 54, no. 3, pp. 179-184, 2014.

[56] A. M. Mengshoel, K. Ø. Forseth, M. Haugen, R. Walle-Hansen, and $\varnothing$. Førre, "Multidisciplinary approach to fibromyalgia. A pilot study," Clinical Rheumatology, vol. 14, no. 2, pp. 165-170, 1995.

[57] A. Michalsen, C. Li, K. Kaiser et al., "In-patient treatment of fibromyalgia: a controlled nonrandomized comparison of conventional medicine versus integrative medicine including fasting therapy," Evidence-Based Complementary and Alternative Medicine, vol. 2013, Article ID 908610, 7 pages, 2013.

[58] W. R. Nielson and M. P. Jensen, "Relationship between changes in coping and treatment outcome in patients with Fibromyalgia Syndrome," Pain, vol. 109, no. 3, pp. 233-241, 2004.

[59] E. Persson, J. Lexell, M. Eklund, and M. Rivano-Fischer, "Positive effects of a musculoskeletal pain rehabilitation program regardless of pain duration or diagnosis," $P M$ and $R$, vol. 4 , no. 5, pp. 355-366, 2012.
[60] S. Ripley, C. R. Ronzio, C. Cozad et al., "Evaluation of a multidisciplinary rehabilitation program for fibromyalgia: a pilot study," Today's Therapeutic Trends, vol. 21, no. 2, pp. 159-184, 2003.

[61] T. Romeyke, H. C. Scheuer, and H. Stummer, "Fibromyalgia with severe forms of progression in a multidisciplinary therapy setting with emphasis on hyperthermia therapy-a prospective controlled study," Clinical Interventions in Aging, vol. 10, pp. 6979, 2014.

[62] M. Salgueiro, X. Basogain, A. Collado et al., "An artificial neural network approach for predicting functional outcome in fibromyalgia syndrome after multidisciplinary pain program," Pain Medicine, vol. 14, no. 10, pp. 1450-1460, 2013.

[63] I. Saral, D. Sindel, S. Esmaeilzadeh, H. O. Sertel-Berk, and A. Oral, "The effects of long- and short-term interdisciplinary treatment approaches in women with fibromyalgia: a randomized controlled trial," Rheumatology International, vol. 36, no. 10, pp. 1379-1389, 2016.

[64] K. F. Stein and A. Miclescu, "Effectiveness of multidisciplinary rehabilitation treatment for patients with chronic pain in a primary health care unit," Scandinavian Journal of Pain, vol. 4, no. 4, pp. 190-197, 2013.

[65] A. L. Suman, B. Biagli, G. Biasi et al., "One-year efficacy of a 3-week intensive multidisciplinary non-pharmacological treatment program fibromyalgia patients," Clinical and Experimental Rheumatology, vol. 27, no. 1, pp. 7-14, 2009.

[66] D. C. Turk, A. Okifuji, J. D. Sinclair, and T. W. Starz, "Interdisciplinary treatment for fibromyalgia syndrome: clinical and statistical significance," Arthritis Care and Research, vol. 11, no. 3, pp. 186-195, 1998.

[67] S. Van Koulil, W. Van Lankveld, F. W. Kraaimaat et al., "Tailored cognitive-behavioural therapy and exercise training improves the physical fitness of patients with fibromyalgia," Annals of the Rheumatic Diseases, vol. 70, no. 12, pp. 2131-2133, 2011.

[68] C. P. van Wilgen, H. Bloten, and B. Oeseburg, "Results of a multidisciplinary program for patients with fibromyalgia implemented in the primary care," Disability and Rehabilitation, vol. 29, no. 15, pp. 1207-1213, 2007.

[69] H. K. Wennemer, J. Borg-Stein, L. Gomba et al., "Functionally oriented rehabilitation program for patients with fibromyalgia: preliminary results," American Journal of Physical Medicine and Rehabilitation, vol. 85, no. 8, pp. 659-666, 2006.

[70] L. M. Worrel, L. E. Krahn, C. D. Sletten, and G. R. Pond, "Treating fibromyalgia with a brief interdisciplinary program: Initial outcomes and predictors of response," Mayo Clinic Proceedings, vol. 76, no. 4, pp. 384-390, 2001.

[71] A. Pfeiffer, J. M. Thompson, A. Nelson et al., "Effects of a 1.5-day multidisciplinary outpatient treatment program for fibromyalgia: a pilot study," American Journal of Physical Medicine and Rehabilitation, vol. 82, no. 3, pp. 186-191, 2003.

[72] T. H. Oh, M. H. Stueve, T. L. Hoskin et al., "Brief interdisciplinary treatment program for fibromyalgia: six to twelve months outcome," American Journal of Physical Medicine and Rehabilitation, vol. 89, no. 2, pp. 115-124, 2010.

[73] A. Vincent, M. O. Whipple, T. H. Oh, J. A. Guderian, D. L. Barton, and C. A. Luedtke, "Early experience with a brief, multimodal, multidisciplinary treatment program for fibromyalgia," Pain Management Nursing, vol. 14, no. 4, pp. 228-235, 2013.

[74] C. O. Townsend, J. L. Kerkvliet, B. K. Bruce et al., "A longitudinal study of the efficacy of a comprehensive pain rehabilitation program with opioid withdrawal: comparison of treatment outcomes based on opioid use status at admission," Pain, vol. 140, no. 1, pp. 177-189, 2008. 
[75] R. M. Gordon, J. R. Corcoran, P. Bartley-Daniele, D. Sklenar, P. R. Sutton, and F. Cartwright, "A transdisciplinary team approach to pain management in inpatient health care settings," Pain Management Nursing, vol. 15, no. 1, pp. 426-435, 2014.

[76] S. Stanos and T. T. Houle, "Multidisciplinary and interdisciplinary management of chronic pain," Physical Medicine and Rehabilitation Clinics of North America, vol. 17, no. 2, pp. 435450, 2006.

[77] K. Karjalainen, A. Malmivaara, M. van Tulder et al., "Multidisciplinary rehabilitation for fibromyalgia and musculoskeletal pain in working age adults," Cochrane Database of Systematic Reviews, no. 2, Article ID CD001984, 2000.

[78] A.-M. Momsen, J. O. Rasmussen, C. V. Nielsen, M. D. Iversen, and H. Lund, "Multidisciplinary team care in rehabilitation: an overview of reviews," Journal of Rehabilitation Medicine, vol. 44, no. 11, pp. 901-912, 2012. 


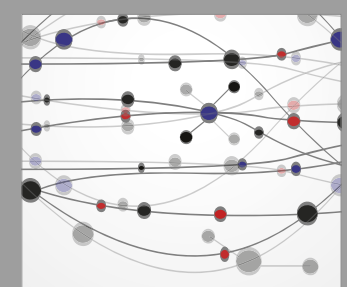

The Scientific World Journal
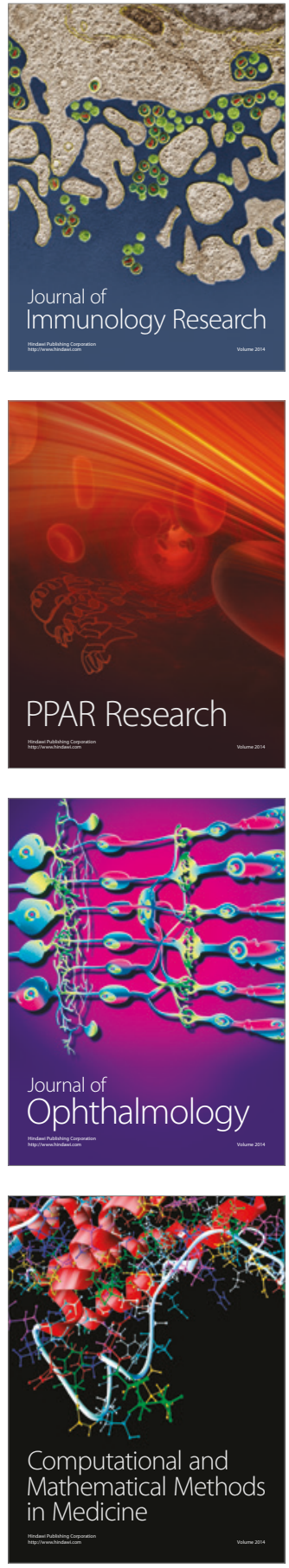

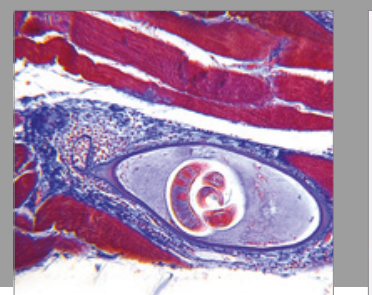

Gastroenterology Research and Practice
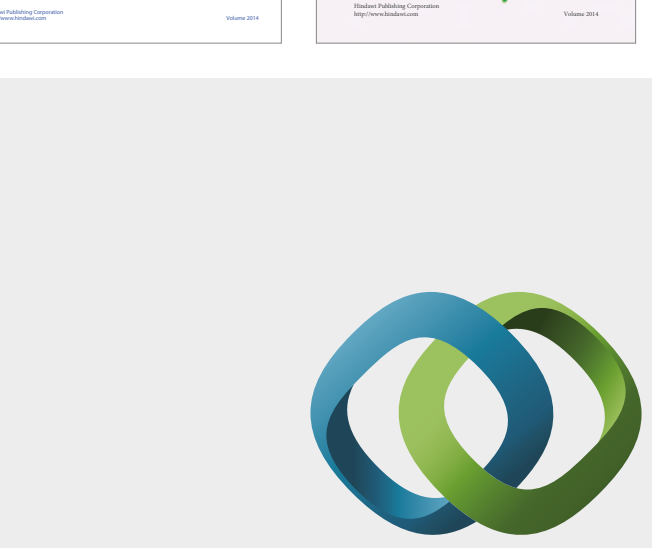

\section{Hindawi}

Submit your manuscripts at

https://www.hindawi.com
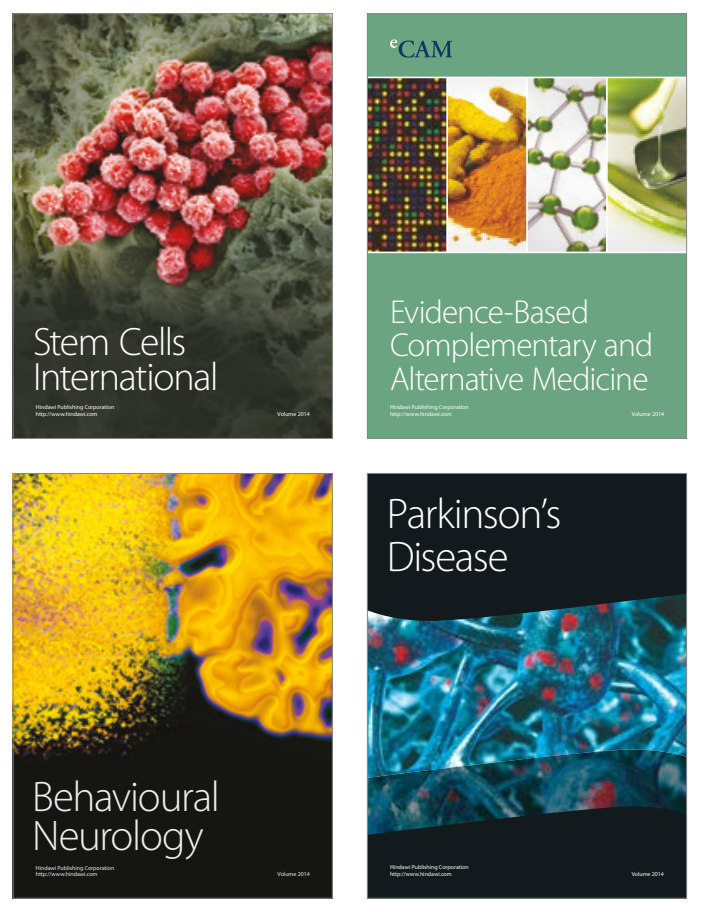
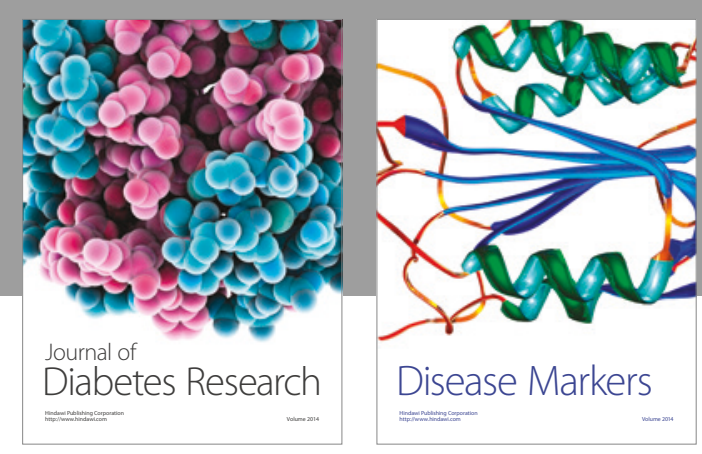

Disease Markers
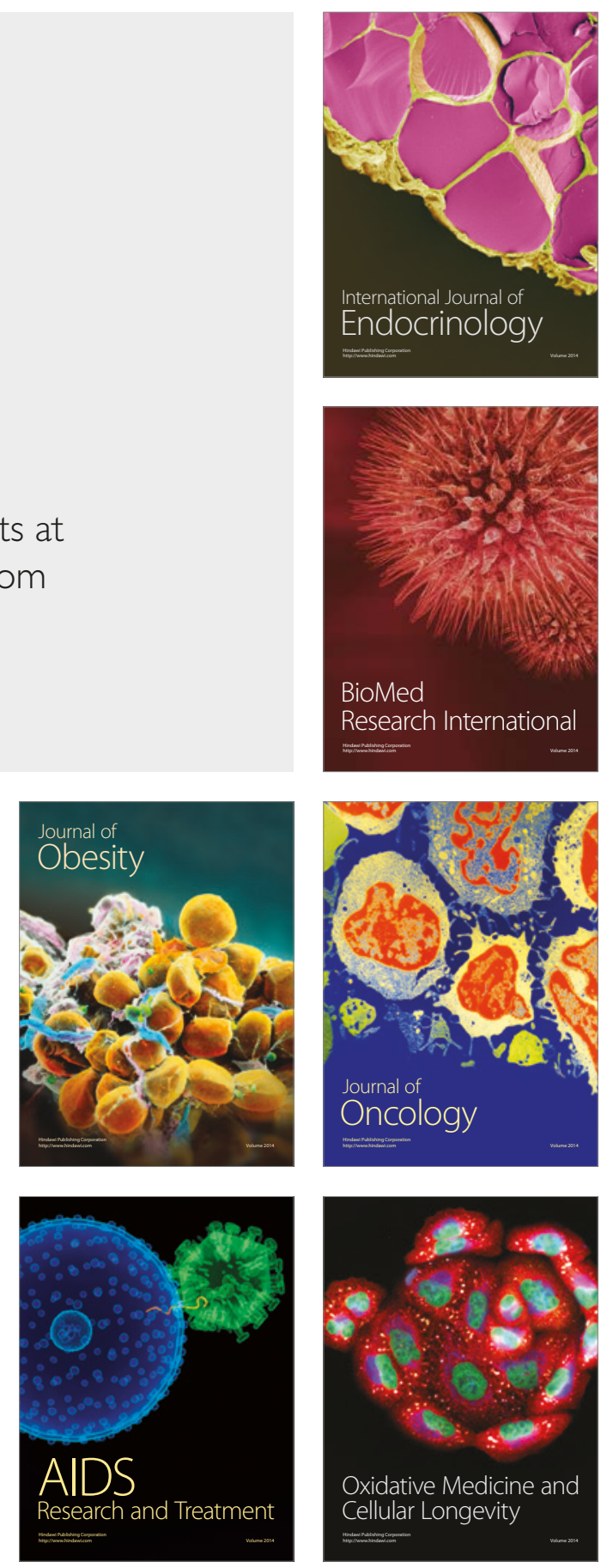